\title{
Clinical observations on response to nasal occlusion in infancy
}

\author{
P. G. F. SWIFT and J. L. EMERY \\ From the Department of Pathology, The Children's Hospital, Sheffield
}

\begin{abstract}
Swift, P. G. F., and Emery, J. L. (1973). Archives of Disease in Childhood, 48, 947. Clinical observations on response to nasal occlusion in infancy. One hundred newborns and 59 infants at 6 weeks of age were observed during a nasal occlusion test. While in rapid eye movement (REM) sleep the proportion of slow and nonresponders was $17 \%$ in the newborn group, it was $44 \%$ in the 6 -week-old group.

The suggestion is made that apnoea occurs as a response to nasal obstruction. It appears to be characteristic of early postneonatal life, is more likely to occur during REM sleep, and may progress to sudden unexpected death.

The tests described might have predictive value in assessing infants thought to be at enhanced risk of sudden unexpected death.
\end{abstract}

There is a widely held conviction that small infants are unable to breathe through their mouths (Beinfield, 1954; Moss, 1965; Ingall et al., 1965; Pracy, 1972), and it has been suggested that nasal obstruction might be a causative factor in sudden unexpected death in infancy (SUDI) (Emery, 1958; Beinfield, 1959; Shaw, 1968, 1970). A small number of infants have been described (Anderson and Rosenblith, 1971) who died unexpectedly in the first year and who recorded slow inadequate neonatal responses to stimuli applied to the nose and mouth during the Modified Graham Behaviour Test (Rosenblith, 1961).

The infant's responses to exogenous stimuli are dependent upon the endogenous 'state' of that individual (Prechtl and Beintema, 1964; Hutt, Lenard, and Prechtl, 1969). As SUDI occurs more commonly at night (Froggatt, Lynas, and MacKenzie, 1971) and probably during sleep (British Medical Journal, 1971), it was considered important to investigate the normal variation of responses to nasal occlusion during sleep states, with the aim of developing a method of examining a normal child that would be both completely safe and give an indication of the child's likely reaction to nasal blockage of any dangerous duration.

\section{Methods}

Two groups were examined: 110 newborn infants and 66 infants with a mean age of 6 weeks.
Newborn group. 110 normal, term (by dates) infants were examined on the 4th postnatal day. 10 of these were withdrawn from the series because of wakefulness, crying, or inadequate recording. 90 of the 100 had Apgar scores of 8 or more at one minute and none of the infants was causing medical concern at the time of examination. On gestational assessment (Dubowitz, Dubowitz, and Goldberg, 1970) 2 infants were shown to be of 36 weeks' gestation. The infants were wheeled in their cots to the ward nursery which had a constant temperature $\left(21-26 \cdot 7^{\circ} \mathrm{C}\right.$ ), low noise level, high humidity, and good light source. Observation of the infant was made by two people for at least one minute to assess the 'state' of the infant, grading according to Prechtl and Beintema (1964) and Hutt et al. (1969) as follows.

State 1. Eyes closed, no eye movements under lids, regular respiration, no movements except occasional startles = Regular or Quiet Sleep.

State 2. Eyes closed, rapid eye movements (REMs) under lids, irregular respiration, no gross movements but small muscle twitches = Irregular or Active Sleep.

State 3. Eyes open, no gross movements = Inactive Wakefulness.

State 4. Eyes open, movement of head, limbs, and trunk.

State 5. Crying = Active Wakefulness.

Transitional states were sometimes recognized, e.g., states 2 to 4 ; eyes closed, REMs, gross body movements.

The child's clothing, position, feeding times, type of feed, and other features of infant care and behaviour were noted.

Stimuli were applied sequentially to the oronasal area as described below and the responses were recorded. 
(a) The tip of the nose was firmly but gently pressed with the examiner's index finger for 15 seconds.

(b) The lip-tap reflex was performed (Prechtl et al., 1967) as a further indication of 'state'.

(c) Each nostril in turn was gently occluded with the tip of the examiner's finger. This showed significant unilateral nasal obstruction or persistent tactile responses.

(d) Both nostrils were gently occluded by the finger tips, a stop watch started, and the responses recorded as accurately as possible. The time taken for an adequate inspiratory breath, gasp, or cry was especially noted. If no adequate air entry occurred within 25 seconds, the obstruction was withdrawn. The procedure was repeated at least once or twice, after a delay of 30 seconds.

The baby was then undressed and a comprehensive neonatal assessment was performed.

Six-week group. A similar procedure was adopted in infants aged $5 \frac{1}{2}$ to $7 \frac{1}{2}$ weeks, while the mother attended hospital for her postnatal check. The infants in this age group were more often awake than asleep. Hence the number adequately tested was smaller than in the newborn group. 66 infants were seen, 59 tested, and 23 of these were asleep. 8 infants were seen in both the newborn period and at 6 weeks, but as they were in different 'states' on each of these occasions, a comparison of responses was invalid.

\section{Results}

Tip of nose response. In the sleeping infant there was commonly no persistent response. Small lip movements occurred but did not persist or extend to avoidance reactions.

Lip-tap reflex. The results of testing in the newborn period are shown in Table $I$. The recorded responses were in general agreement with Prechtl et al. (1967). The monosynaptic jerk reflex was more often positive in state 1 (non-REM sleep), and the polysynaptic protrusion reflex was more often positive in state 2 (REM sleep). However,

TABLE I

Results of lip-tap reflex in newborn period

\begin{tabular}{|c|c|c|c|c|c|c|}
\hline & \multirow{2}{*}{ No. } & \multicolumn{5}{|c|}{ Clinical 'state' of infant * } \\
\hline & & 1 & $1-2$ & 2 & $2-4$ & Other \\
\hline $\begin{array}{l}\text { No test performed } \\
\text { Equivocal response to test } \\
\text { No response } \\
\text { Jerk of lip } \\
\text { Protrusion of lip } \\
\text { Jerk and protrusion of lip }\end{array}$ & $\begin{array}{r}7 \\
8 \\
49 \\
20 \\
9 \\
7\end{array}$ & $\begin{array}{l}7 \\
9 \\
-\end{array}$ & $\begin{array}{l}5 \\
2 \\
1 \\
1\end{array}$ & $\begin{array}{r}26 \\
3 \\
4 \\
3\end{array}$ & $\begin{array}{c}11 \\
2 \\
4 \\
2\end{array}$ & $\overline{4}$ \\
\hline Total & 100 & & & & & \\
\hline
\end{tabular}

$\star$ See Methods. the responses were so frequently negative or equivocal that the reflex in this series must be considered only minimally helpful in the assessment of state.

Unilateral nasal occlusion. A variety of responses was observed. Most often there was a transient evoked lip or head movement. In very few cases did avoidance reactions persist. Because responses were minimal and transitory, it was concluded that the sleeping infant, whether in quiet or active sleep, would happily breathe through one nostril and was not persistently reactive to simple tactile stimuli.

Bilateral nasal occlusion. Responses fell into 5 grades.

Grade $A$, transient or no tactile response. The lips open within 25 seconds and the infant mouthbreathes without waking.

Grade $B$, responses occur after a delay of up to 20 seconds. Signs of a protest build up and arousal from sleep seems imminent. There is often a rapid expiration thrusting the tongue down and the lips open followed by a rapid gasping inspiration and then crying. If obstruction of the nose continues, crying persists, but if removed the infant often returns to the original state.

Grade $C$, avoidance reactions (head retraction and side-to-side movements) occur after a delay of up to 20 seconds. A protest builds up. Mouthbreathing is then attempted through open lips but noisy moist 'snorting' sounds are made at the back of the throat. Within 25 seconds crying or more than one inspiration with a clear airway ensures adequate ventilation.

Grade $D$, similar responses to $\mathrm{C}$ occur, but after marked obstruction at the back of the throat, crying or more than one inspiration with a clear airway ensures adequate ventilation within 25 seconds.

Grade $E$, insignificant avoidance reaction occurs. There is no struggle, cry, mouth breathing, or attempts at mouth breathing. The infant shows no arousal from sleep in 25 seconds.

Some responses had the characteristics of two of these grades and were categorized with both letters concerned.

In the newborn group the most important results concern the two extremes of responses, namely grades $A$ and $E$ (Table II). Response grade E, with no arousal and no attempt to initiate oral respiration, was found in $3 \%$ of infants, all of whom were sleeping with REMs present. In addition, $10 \%$ did 
TABLE II

Graded responses to bilateral occlusion with reference to observed state in newborn group

\begin{tabular}{l|c|c|c|c|c|c|c|c|c}
\hline $\begin{array}{l}\text { Grade of } \\
\text { response }\end{array}$ & A & A-B & B & B-C & C & C-D & D & E & Total \\
\hline State 1 & - & - & 16 & 1 & 1 & 1 & - & - & 19 \\
$1-2$ & - & - & 4 & - & 2 & - & - & 1 & 7 \\
2 & 4 & - & 22 & 1 & 4 & 1 & 7 & 2 & 41 \\
$2-4$ & 1 & 1 & 13 & 2 & 5 & 1 & 2 & - & 25 \\
Other & - & - & 6 & - & 1 & - & 1 & - & 8 \\
\hline Total & 5 & 1 & 61 & 4 & 13 & 3 & 10 & 3 & 100 \\
\hline
\end{tabular}

not initiate mouth breathing within 25 seconds but struggled against the obstruction (grade D). Most of these were asleep with REMs. Grade A responses were shown by $5 \%$ of infants who were also in REM sleep.

Of the total number tested, $87 \%$ were able to initiate what was considered an adequate inspiration within 25 seconds of nasal obstruction. All the newborn infants who were awake (i.e. states 3,4 , and 5) gasped or cried adequately, and usually within 10 seconds. None of the 10 newborn infants with Apgar scores of less than 7 at one minute fell into grade $\mathrm{E}$ group, but one of the infants of 36 weeks' gestation did so.

In the 6-week group $60 \%$ of the infants were in wakeful states (Table III). Probably because of this bias, $15 \%$ of infants tested (all awake) were able to initiate quiet efficient mouth breathing (grade A), but $44 \%$ ( 7 out of 16 ) of the infants asleep with REMs showed poor responses (grades $\mathrm{E}$ and $\mathrm{D}$ ). 4 out of 11 6-week babies in definable state 2 REM sleep did not struggle or become aroused from sleep to establish oral respiration.

Table IV shows the average times taken to make an adequate inspiration in the two groups.
TABLE IV

Average response times to make an adequate inspiration

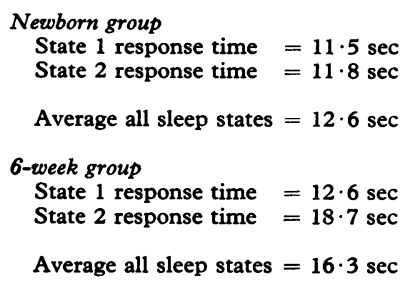

\section{Discussion}

Asphyxia caused by overlying (Old Testament, Kings, I; Templeman, 1892; Richards and McIntosh, 1972), smothering (Banks, 1958; Coe and Hartman, 1960), accidental suffocation (Barrett, 1954; Boucher, 1958; British Medical Journal, 1958), laryngospasm (Bergman, 1970; Pinkham and Beckwith, 1970), and nasal obstruction (Emery, 1958; Shaw, 1970) have all been suggested as possible mechanical causes of sudden unexpected death in infancy. Beinfield (1959) warned that choanal atresia should be considered, but this has not been substantiated in any subsequent survey (Valdés-Dapena, 1967). However, he did point out, as other authors have (Eichenwald and McCracken, 1969), that a few infants with bilateral atresia of the posterior nares survive by breathing through their mouths, and the deformity may be discovered at a later age.

Moss (1965) suggested that infants in the first few months are 'obligatory nose breathers' due to the high cephalad position of the cervical viscera with close apposition of the soft palate to the tongue and epiglottis, the so-called 'velo-lingual' and 'veloepiglottic' sphincters. Experiments have been

TABLE III

Graded responses to bilateral occlusion with reference to observed state in 6-week group

\begin{tabular}{|c|c|c|c|c|c|c|c|c|c|}
\hline $\begin{array}{l}\text { Grade of } \\
\text { response }\end{array}$ & A & A-B & B & B-C & C & C-D & D & E & Total \\
\hline $\begin{array}{c}\text { State } 1 \\
1-2 \\
2 \\
2-4 \\
{ }^{3} \\
\text { Other }\end{array}$ & $\begin{array}{l}\bar{z} \\
\bar{z} \\
9\end{array}$ & $\begin{array}{l}= \\
\frac{7}{3}\end{array}$ & $\begin{array}{r}3 \\
3 \\
2 \\
1 \\
10\end{array}$ & $\begin{array}{l}\bar{z} \\
\bar{z} \\
=\end{array}$ & $\begin{array}{l}\frac{2}{2} \\
\frac{1}{8}\end{array}$ & $\begin{array}{l}= \\
\bar{z} \\
=\end{array}$ & $\begin{array}{l}- \\
2 \\
1 \\
2 \\
1 \\
4\end{array}$ & $\begin{array}{l}\bar{z} \\
\overline{-}\end{array}$ & $\begin{aligned} 5 & (8 \cdot 3) \\
2 & (3 \cdot 3) \\
11 & (18 \cdot 3) \\
5 & (8 \cdot 3) \\
2 & (3 \cdot 3) \\
34 & (56 \cdot 6)\end{aligned}$ \\
\hline Total & $\begin{array}{c}9 \\
(15)\end{array}$ & $\begin{array}{c}3 \\
(5 \cdot 0)\end{array}$ & $\begin{array}{c}19 \\
(31 \cdot 6)\end{array}$ & $\begin{array}{c}1 \\
(1 \cdot 6)\end{array}$ & $\begin{array}{c}13 \\
(21 \cdot 6)\end{array}$ & 二 & $\begin{array}{c}10 \\
(16 \cdot 6)\end{array}$ & $\begin{array}{c}4 \\
(6 \cdot 6)\end{array}$ & $\begin{array}{ll}59 & \\
& (100)\end{array}$ \\
\hline
\end{tabular}

Note: Fercentage in brackets. 
described (Cross, 1972; Cross and Lewis, 1971) in which sleeping infants, encased in a whole-body plethysmograph, displayed a markedly decreased tidal volume when their pharynx was obstructed by the cuff of the plethysmograph. This ominous situation did not arouse some infants from their sleep.

Shaw (1970) stated that more than $50 \%$ of neonates, about $70 \%$ of 3-month infants, and almost all 6-month infants are able to mouth breathe. He surmised that one in 400 infants with an obstructed nose just dies without a struggle (Shaw, 1972), this proportion being simply the incidence of cot deaths! His figures were based on personal observations of babies brought into hospital wards and clinics, whose noses were occluded by their mothers or by himself (E. B. Shaw, personal communication, 1972). There is little mention of the 'state' of the infants tested.

The present investigation was conducted with some hesitation for if the obligatory nose breathing thesis were true, then occluding an infant's nose could result in death. Precautions were taken in having resuscitation equipment at hand, and with the limit imposed of 25 seconds' nasal occlusion, no child caused any medical concern. Within that time limit it was possible to observe a series of different responses which might well have clinical importance.

When their noses were occluded, $5 \%$ of sleeping newborns were able to mouth breathe successfully. $82 \%$ were stimulated sufficiently during sleep to gasp or cry. But $13 \%$ either took longer than 25 seconds to cry or did not attempt to initiate an oral airway.

The mouth-breathing responses in some of the 6-week infants seemed to differ from those in the newborn, particularly during REM sleep. 7 out of $16(44 \%)$ of the older infants asleep with REMs were wholly or partially unable to establish an oral airway within 25 seconds as compared with 11 of $66(17 \%)$ newborns studied. 4 out of 11 older infants who were in steady state 2 (REM sleep) exhibited no signs of arousal when nasal occlusion was performed. The 6-week infants who did arouse and struggle exhibited far more obstructive sounds at the back of the throat than the newborn infants.

A further indication of the diminishing efficiency of the older group was shown in the average times taken to make an adequate inspiration (either gasping or crying). The average was considerably shorter in the newborn than in the 6-week infant.

Five infants were sucking dummies at the time of nasal occlusion. They were able to breathe through the mouth around the dummies without awakening, but as the dummies were removed, the infants showed pharyngeal obstructive signs similar to the other infants. Presumably the dummy pushes the tongue down from the soft palate breaking the velo-lingual sphincter.

Several explanations may be advanced for the poor oral responses in the 6-week babies. The anatomy of the infant's mouth and pharynx which hinders an oral respiratory route has been mentioned. During REM (paradoxical) sleep the larynx and pharyngeal muscles are atonic as reflected by electromyography (Oswald, 1966), monosynaptic reflexes are commonly abolished, and polysynaptic reflexes are diminished (Lenard, Von Bernuth, and Prechtl, 1968). These features, combined with an inability to be activated quickly from REM sleep (Jouvet, 1967), might account for the noisy obstructive sounds at the back of the throat and for the poor arousal of some infants.

In the newborn the clinical delineation of sleeping states is more difficult than in older infants and adults (Sterman, 1972). Atypical or transitional sleep constitutes approximately $10 \%$ of total sleep time in the term infant (Parmelee et al., 1967), and can only be readily defined by polygraphic recording techniques. Many of the newborns tested may have been in this transitional state and were more readily stimulated to establish an airway than the 6-week infants with more mature REM sleep cycles.

REM sleep is associated with a higher incidence of periodic breathing, and at the onset of each flurry of REM cycles there is a systematic decrease in amplitude of respiration with a tendency towards apnoea (Aserinsky, 1965). Laboratory sleep studies monitoring heart rate, respiratory rhythms, and eye movements in a group of infants referred because of recurrent cyanotic attacks revealed frequent short periods of apnoea. They were most marked during REM sleep and diminished with increasing age (A. Steinschneider, personal communication, 1970). Some of the prolonged apnoeic spells required vigorous resuscitation, which suggests that the sudden apnoea, closely associated with REM sleep and age dependent, may be part of the pathway leading to sudden death. Similar prolonged apnoeic attacks have been provoked in immature monkeys (French, Morgan, and Guntheroth, 1972) by nasal occlusion or cold thermal stimuli applied to the face (suggestive of the dive reflex, Wolf, 1966). The reflex apnoea disappeared as the monkeys grew slightly older.

The present study provides evidence suggesting that 5 to $10 \%$ of all the sleeping newborn infants showed delayed initiation of mouth breathing after nasal occlusion during REM sleep and that this 
proportion increased at 5 to 7 weeks. Prolonged delay in the response to airway obstruction could cause hypoxia or trigger a reflex which, during REM sleep, might produce fatal apnoea. As the infant matures beyond the age of 5 to 6 months, the apnoea response disappears, except in a few unusual cases, and it is at a similar stage of maturity that the mouth breathing reflex is established in the majority of children.

The tests described here could have clinical importance and could be applied to a group of infants thought to be at enhanced risk of unexpected death. However, until such a trial is carried out it would be quite unjustifiable to suggest that a child showing a delayed or absent mouth breathing response is liable to sudden unexpected death.

Active assistance was given by Mrs. P. M. McWeeny (supported by The Foundation for the Study of Infant Deaths), Mrs. B. Owen, and Mrs. N. Lockwood, and the staff of the Nether Edge Hospital Maternity Unit. We thank Dr. Bruce Smith, paediatrician in charge of the infants, and Professor R. S. Illingworth for advice.

\section{REFERENCES}

Anderson, R. B., and Rosenblith, J. F. (1971). Sudden unexpected death syndrome. Early indicators. Biology of the Neonate, 18, 395.

Aserinsky, E. (1965). Periodic respiratory pattern occurring in conjunction with eye movements during sleep. Science, 150, 763.

Banks, A. L. (1958). An enquiry into sudden death in infancy. Monthly Bulletin of the Ministry of Health and the Public Health Laboratory Service, 17, 182.

Barrett, A. M. (1954). Sudden death in infancy: the asphyxia hypothesis. In Recent Advances in Paediatrics, p. 315 . Ed. by D. Gairdner. Churchill, London.

Beinfield, H. H. (1954). Bilateral bony atresia of the posterior nares in a one-month premature infant who survived. Fournal of Pediatrics, 45, 679.

Beinfield, H. H. (1959). Ways and means to reduce infant mortality due to suffocation. Fournal of the American Medical Association, $170,647$.

Bergman, A. B. (1970). Summary statement. Sudden infant death syndrome. Proceedings of the Second International Conference on Causes of Sudden Death in Infants, p. 209. Ed. by A. B. Bergman, J. B. Beckwith, and C. G. Ray. University of Washington Press, Seattle.

Boucher, C. A. (1958). Discussion on the prevention of accidents in childhood. Proceedings of the Royal Society of Medicine, 51, 395.

British Medical fournal (1958). Leading article. Death from obscure causes in infancy, $2,684$.

British Medical fournal (1971). Leading article. Cot deaths, 4, 250.

Coe, J. I., and Hartman, E. E. (1960). Sudden unexpected death in infancy. Fournal of Pediatrics, 56, 786.

Cross, K. W. (1972). Sudden and unexpected deaths in infancy (cot deaths). Sir Samuel Bedson Symposium, Cambridge, 1970, p. 57. Ed. by F. E. Camps and R. G. Carpenter. John Wright and Sons, Bristol.

Cross, K. W., and Lewis, S. R. (1971). Upper respiratory obstruction and cot death. Archives of Disease in Childhood, 46, 211.

Dubowitz, L. M. S., Dubowitz, V., and Goldberg, C. (1970). Clinical assessment of gestational age in the newborn infant. fournal of Pediatrics, 77, 1.
Eichenwald, H. F., and McCracken, G. H., Jr. (1969). The upper respiratory tract. In Textbook of Pediatrics, p. 883. Ed. by W. E. Nelson, V. C. Vaughan, and R. J. McKay. Saunders, London.

Emery, J. L. (1958). Sudden and unexpected death in infancy. Medical World, 89, 210.

French, J. W., Morgan, B. C., and Guntheroth, W. G. (1972). Infant monkeys - a model for crib death. American fournal of Diseases of Children, 123, 480.

Froggatt, P., Lynas, M. A., and MacKenzie, G. (1971). Epidemiology of sudden unexpected death in infants (cot death) in Northern Ireland. British fournal of Preventive and Social Medicine, 25, 119.

Hutt, S. J., Lenard, H. G., and Prechtl, H. F. R. (1969). Psychophysiological studies in newborn infants. In Advances in Child Development and Behavior, Vol. 4, p. 127. Ed. by L. P. Lipsitt and $\mathrm{H}$. W. Reese. Academic Press, New York and London.

Ingall, M., Glaser, J., Meltzer, R. S., and Dreyfuss, E. M. (1965). Allergic rhinitis in early infancy. Pediatrics, $35,108$.

Jouvet, M. (1967). Neurophysiology of the states of sleep. Physiological Revievws, 47, 117.

Lenard, H. G., Von Bernuth, H., and Prechtl, H. F. R. (1968). Reflexes and their relationship to the behavioural state in the newborn. Acta Paediatrica Scandinavica, 57, 177.

Moss, M. L. (1965). The veloepiglottic sphincter and obligate. Nose breathing in the neonate. Fournal of Pediatrics, 67, 330.

Old Testament. Kings, I, 3, 19.

Oswald, I. (1966). Sleep, p. 100. Penguin Books, Harmondsworth, Middlesex.

Parmelee, A. H., Jr., Wenner, W. H., Akiyama, Y., Schultz, M., and Stern, E. (1967). Sleep states in premature infants. Developmental Medicine and Child Neurology, 9, 70.

Pinkham, J. R., and Beckwith, J. B. (1970). Vocal cord lesions in the sudden infant death syndrome. Sudden Infant Death Syndrome. Proceedings of the Second International Conference on Causes of Sudden Death in Infants, p. 104. Ed. by A. B. Bergman, J. B. Beckwith, and C. G. Ray. University of Washington Press, Seattle.

Pracy, R. (1972). The diagnosis of respiratory obstruction in infants and small children. Nursing Times, 68, 930.

Prechtl, H. F. R., and Beintema, D. J. (1964). Neurological Examination of the Full-Term Newborn Infant. Clinics in Developmental Medicine, No. 12. Heinemann, London.

Prechtl, H. F. R., Kerr Grant, D., Lenard, H. G., and Hrbek, A. (1967). The lip-tap-reflex in the awake and sleeping newborn infant: a polygraphic study. Experimental Brain Research, 3, 184.

Richards, I. D. G., and McIntosh, H. T. (1972). A confidential inquiry into 226 consecutive infant deaths. Archives of Disease in Childhood, 47, 697.

Rosenblith, J. F. (1961). The modified Graham behaviour test for neonates. Biology of the Neonate, 3, 174 .

Shaw, E. B. (1968). Sudden unexpected death in infancy syndrome. American Fournal of Diseases of Children, 116, 115.

Shaw, E. B. (1970). Sudden unexpected death in infancy syndrome. American Fournal of Diseases of Children, 119, 416.

Shaw, E. B. (1972). Quoted in Sudden and Unexpected Deaths in Infancy (Cot Deaths). Sir Samuel Bedson Symposium, Cambridge, 1970, p. 70 . Ed. by F. E. Camps and R. G. Carpenter. John Wright and Sons, Bristol.

Sterman, M. B. (1972). The basic rest-activity cycle and sleep. In Sleep and the Maturing Nervous System, p. 176. Ed. by C. D. Clemente, D. P. Purpura, and F. E. Mayer. Academic Press, New York and London.

Templeman, C. (1892). Two hundred and fifty-eight cases of suffocation of infants. Edinburgh Medical fournal, 38, 322.

Valdés-Dapena, M. A. (1967). Sudden and unexpected death in infancy: a review of the world literature 1954-1966. Pediatrics, $39,123$.

Wolf, S. (1966). Sudden death and the oxygen-conserving reflex. American Heart fournal, 71, 840.

Correspondence to Professor J. L. Emery, Department of Pathology, The Children's Hospital, Western Bank, Sheffield S10 3BR. 